\title{
NARRATIVISM, REDUCTIONISM AND FOUR-DIMENSIONALISM
}

\author{
Alfonso Muñoz Corcuera \\ bttps://orcid.org/0000-0003-0098-1489 \\ Universidad Complutense de Madrid \\ bttps://doi.org/10.15304/ag.40.2.6713
}

\section{Resumen}

En una exitosa serie de artículos, Schroer y Schroer han presentado una teoría narrativa reduccionista de la identidad personal (R. Schroer, 2013, J. W. Schroer y Schroer, 2014). Al hacerlo, afirman que su teoría reduccionista tiene ventajas sobre las teorías narrativas tradicionales. En este artículo pretendo demostrar que se equivocan. Aunque es posible defender una teoría narrativa reduccionista, la teoría de los Schroer tiene un problema de circularidad. Y resolver este problema provoca que la teoría de los Schroer tenga muchos más inconvenientes que las teorías narrativas no-reduccionistas. En consecuencia, los Schroer deberían presentar una nueva y mejorada teoría narrativa reduccionista o aceptar que las teorías narrativas no-reduccionistas están mejor equipadas para dar cuenta del problema de la identidad personal.

Palabras clave: identidad personal, narratividad, reduccionismo, cuatridimensionalismo.

\section{Abstract}

In a successful series of papers, Schroer and Schroer presented a reductionist narrative account of personal identity (R. Schroer, 2013; J. W. Schroer \& Schroer, 2014). They claimed that their reductionist account had advantages over traditional narrative theories. In this paper I intend to show that they were wrong. Although it is possible to defend a reductionist narrative account, the Schroers' theory has a problem of circularity. And solving that problem will cause their theory to have much more problems than non-reductionist narrative theories. Consequently, they should either present a new and improved reductionist narrative account, or accept that non-reductionist narrative theories are better suited to account for the problem of personal identity.

Keywords: personal identity, narrativity, reductionism, four-dimensionalism.

Recibido: 06/04/2020. Aceptado: 30/06/2020. 


\section{Introduction}

Narrative theories of personal identity were born in the eighties of the past century as an alternative to psychological continuity theories. They shared with those psychological continuity theories their inspiration on the widely influential view held by Locke in the seventeenth century. For example, they shared with them the broadly Lockean view that persons are to be defined in mental terms (Locke, 1975, p. 335), as well as the belief that personal identity should be understood as a forensic notion (Locke, 1975, p. 346). Thus, both psychological continuity theories and narrative theories could be considered as different forms of neo-Lockeanism. However, in spite of that general agreement, narrative identity theories considered psychological continuity theories as being deeply flawed. Most of all, because of their endorsement of reductionism regarding personal identity.

Nevertheless, in a successful series of papers, Schroer and Schroer have argued that the divisive line between psychological continuity theories and narrative identity theories is more apparent than real (see R. Schroer, 2013; J. W. Schroer \& Schroer, 2014). According to the Schroers, it is possible to endorse both, reductionism and narrativism. In fact that newly conceived reductionist narrative account of personal identity would have advantages over both reductionist psychological continuity theories and non-reductionist narrative identity theories.

Although the Schroers make an important contribution demonstrating that narrativism is compatible with reductionism, in this paper I intend to show that their case against non-reductionist narrative theories is not as strong as it could seem at first. Most of all, because their reductionist view has a problem of circularity that is difficult to solve.

My argument will be as follows: In Section 2 I will present the Schroers' theory, highlighting why their theory has a problem of circularity. In Section 3 I will present the options that they have to solve that problem, defending why I think that they should accept Parfit's reductionism. Finally, in Section 4 I will show why a narrative identity theory that endorses Parfitian reductionism has much more problems than a non-reductionist narrative identity theory. In light of my argument, I will conclude that the Schroers should either present a new and improved reductionist narrative account or accept that non-reductionist narrative theories are better suited to account for the problem of personal identity. 


\section{The Schroers' reductionist narrative account of personal identity}

The Schroers are concerned with the persistence question of personal identity. They frame their proposal in the popular cluster of personal identity theories that follow Locke's views on the matter. The reason to do that is that, according to them, the best way to capture the connections of personal identity "to other notions such as responsibility, compensation, etc. is through understanding personal identity in psychological terms" (J. W. Schroer \& Schroer, 2014, p. 447). Thus their account "construes personal identity as a forensic notion built out of certain psychological elements" (J. W. Schroer \& Schroer, 2014, p. 447).

This is the same project pursued by supporters of psychological continuity theories in the second half of the $20^{\text {th }}$ century. The Schroers consider that these philosophers were "on the right track" (J. W. Schroer \& Schroer, 2014, p. 464). However, the concept of psychological continuity failed to capture one important feature of our experience of being a person: the importance of activities of self-interpretation/creation. As a solution they propose to refine this concept with the help of narrative theories of personal identity. Thus, they defend that personal identity depends not on psychological continuity, but on narrative continuity - where narrative continuity is understood as overlapping chains of narrative connectedness, and narrative connectedness is just psychological connectedness plus the disposition to give a narrative explanation of some mental states (J. W. Schroer \& Schroer, 2014, p. 459). In this regard, they present their theory not as a replacement of previous psychological continuity theories of personal identity, but as a refinement (J. W. Schroer \& Schroer, 2014, p. 464). Specifically, they depart from Lewis' four-dimensionalist account of personal identity to present their view in the following terms:

An earlier person stage $\mathrm{X}$ and a later person stage $\mathrm{Y}$ are two stages of the same person if:

(1) There is narrative continuity [...] between some of the mental states/actions of $\mathrm{X}$ and some of the mental states/actions of $\mathrm{Y}$

(2) These mental states are causally related to each other in the right way

(3) There is no branching (J. W. Schroer \& Schroer, 2014, p. 463)

The first thing that can be noted regarding their view is that they talk about person stages. This is typical of four-dimensionalist accounts of personal identity that assume that persons persist through time in virtue of having temporal parts. That is, they hold that a person is never wholly present at a given time, because persons are four-dimensional "worms" that 
stretch out through space-time. At a given time there only is a temporal part of that four-dimensional worm. In this regard, the Schroers follow Lewis and conceive a person stage as "being a temporal part of a person" (J. W. Schroer \& Schroer, 2014, p. 447). Moreover, they think that person stages are much like short-lived persons that can do everything a person can do in a short period of time. Like persons, person stages can walk and talk, possess different mental and physical properties... The only difference is that person stages only exist for a short period of time.

According to the Schroers, giving an account of personal identity in terms of person stages is also what makes their proposal a reductionist account: it reduces persons to aggregates of person stages. In clarifying their view, the Schroers $(2014$, p. 448$)$ note that reductionism, as they understand it, can be subdivided into two more specific and fully independent claims:

Ontological Reductionism: All facts about persons depend upon, and are ontologically settled by, facts about person stages.

Epistemological Reductionism: All facts about persons can be analyzed, without remainder, in terms of facts about person stages.

The Schroers note that their position is not committed to epistemological reductionism, and they focus their argument on ontological reductionism (J. W. Schroer \& Schroer, 2014, p. 448). Thus, hereafter, when I talk about the Schroers' reductionism I will be referring to their ontological reductionism, unless otherwise stated, ignoring any problems related to their epistemological reductionism (see Noonan, 2003, p. 101; Shoemaker, 1984, p. 101).

However, even if we focus exclusively on their ontological reductionism, the Schroers' theory has a problem of circularity: they want to reduce persons to person stages, but person stages are persons themselves. To see why this is so, we can start by noting that the Schroers conceive person stages as having some temporal duration. Robert Schroer talks about one second as a possible duration for person stages (R. Schroer, 2013, p. 351). But however short it is the period that they propose as the possible duration of a person stage, a person stage can still do everything a person can do in that time. They can walk and talk, have belief and desires, memories and intentions... Given this, it is hard to deny that person stages are persons themselves, because the only difference between persons and person stages is the amount of time that they exist. And persons are persons regardless of the amount of time that they happen to live. Thus, it is not that person stages are "much like" short lived persons, as the Schroers claim (J. W. Schroer \& Schroer, 2014, p. 447). They are short lived persons. And short lived persons are... 
well, persons. Thus, what the Schroers's reductionism entails is that all facts about persons depend upon, and are ontologically settled by facts about persons!

One could think that the Schroers could get rid of this circularity problem just by accepting Lewis' definition of what a person is. Lewis avoids the conclusion that person stages are persons because he defines persons in a very specific sense: they are maximal R-interrelated aggregates of person stages (Lewis, 1983, pp. 59-60). That is, a person is the aggregate of all the consecutive person stages that are interrelated by the relation of mental continuity. Thus, a person stage is not a person because it is psychologically continuous with other person stages. ${ }^{1}$ This strategy seems to solve the problem of circularity for the Schroers. However, it does not do it satisfactorily. First, because it allows the Schroers to reduce persons to person stages at the price of making person stages as complex as persons. So, they would not be reducing persons to more basic entities. And second, because it does not really solve the problem of circularity. It just turns it into a problem of infinite regress.

With regard to the first objection, Lewis claims that a person stage is not a person because it is psychologically continuous with other person stages. However, if a person stage were not psychologically continuous with any other person stage, that person stage would be a person. Think about a person who only exists for one second, thus consisting of a single person stage. In this regard, even if person stages are not persons, it is not because of their intrinsic properties. They would be persons if there were no other person stages around them (Johnston, 2010, p. 65). This implies that, whenever there is a person stage, there is at least a person. Thus, person stages cannot be thought as more basic entities than persons: they are just as complex. To see why this is unsatisfactory, compare the Schroers' reductionism with what is claimed when someone says that mental properties can be reduced to physical properties. In this second case, mental properties are conceived as being dependent on very complex physical properties, so that you can have more simple physical properties without there being mental properties. But when the Schroers claim that persons can be reduced to person stages, they cannot have person stages without having persons, because

${ }^{1}$ In this regard, Lewis' disciple Johnston notes that it is arbitrary to deny personhood to person stages, because they "are sufficiently person-like to deserve the special respect that we extend to persons" (Johnston, 2010, p. 65). This creates some serious problems for Lewis' theory (and, consequently, for the Schroers' theory) related to the ethical aspect of personal identity (see Johnston, 2010, pp. 62-68). 
person stages have all the necessary properties to be persons. If they are not persons, it is not because some metaphysical fact, but because an arbitrary terminological decision.

Regarding the second objection, even if we were to accept this unsatisfactory reductionism, it would still be affected by a problem of infinite regress. This problem becomes evident if we focus on the specific duration that the Schroers grant to person stages. As I said above, Robert Schroer proposes one second as the possible duration of a person stage. But if we can imagine a person who exists only for one second, we can also imagine a person who exists only for half a second. And if this hypothetical person is composed of any person stages (and according to the Schroers' reductionism, they has to be), it must be person stages that lasts less than one second. But if there are person stages that last less than one second, then the Schroers' one-second person stages can be reduced to even shorter person stages. And since we can always come up with shorter person stages, this process would repeat infinitely. Interestingly, we can note that this is precisely why Lewis does not specify any duration for person stages and, in the end, rejects the kind of reductionism proposed by the Schroers:

When I say that persons are maximal R-interrelated aggregates of person-stages, I do not claim to be reducing "constructs" to "more basic entities". (Since I do not intend a reduction to the basic, I am free to say without circularity that person-stages are R-interrelated aggregates of shorter person-stages.) (Lewis, 1983, p. 77)

Consequently, the problem of circularity makes the Schroers' reductionism untenable, and thus their theory is fatally flawed. As a result, they need a solution to the problem of circularity. ${ }^{2}$

\section{The two horns of the reductionist dilemma}

As I see it, the Schroers have two options to solve the problem of circularity. The first one would be to maintain their four-dimensionalist reductionism and define person stages in such a way that there is a significant metaphysical difference between person stages and persons. The second option would be to abandon the project of reducing persons to person stages and try to reduce persons to something else.

Regarding the first horn of this dilemma, I do not see how it could be a viable option. If the Schroers want to take this path, they will need to give

${ }^{2}$ I would like to thank one anonymous referee for pressing this issue and making me rethink what the problem of circularity specifically consisted in. 
us a coherent account of how person stages might be significantly different in a metaphysical sense from persons. And this seems to be a doomed task. Consequently, I will not pursue this line of reasoning. However, I will present two reasons why, regardless of whether the first horn of the dilemma is a viable option or not, I think that the Schroers should take the second horn.

First, the Schroers claim that a typical example of a non-reductionist theory would be a dualist one that maintains that personal identity depends on the existence of a non-physical soul (J. W. Schroer \& Schroer, 2014, p. 448). That is, it seems that they are thinking about their reductionism as implying a rejection of dualism. However, their four-dimensionalist reductionism is not incompatible with the claim that persons have immaterial souls. A four-dimensionalist dualist might hold that a person stage is composed of a body stage and a soul stage and accept that all facts about persons depend upon, and can be analyzed in terms of, facts about person stages. Surely, the Schroers can distance themselves from dualism just by conceiving person stages as being merely physical entities. However, it seems that they do not want their reductionism to be compatible with both dualism and materialism; it seems that they want their reductionism to imply a rejection of dualism. If that is what the Schroers want, then they should consider adopting a different type of reductionism.

Second, the Schroers referred to the landscape of the debate over personal identity as having a very precise outline. They claimed that, generally speaking, psychological continuity theories and narrative identity theories are located at opposite ends of a spectrum. The former are reductionists, while the latter are non-reductionist. The relevance of their theory is that it challenges this view: it is reductionist and narrativist at the same time. I will insist on this, because it is of crucial importance. They want philosophers to pay attention to their theory because it is different from other narrative theories in a very specific sense: it is reductionist just as traditional psychological continuity theories (but not narrative theories) are. Thus, the Schroers need to endorse a reductionist position that is endorsed by psychological continuity theories but not by narrative identity theories. Unfortunately, their four-dimensionalist reductionism does not fit the bill.

The notion of reductionism that is behind the distinction between reductionist psychological continuity theories and narrative identity theories is the one that Parfit presented in his Reasons and Persons. In this book, Parfit defined reductionism with a series of claims. If we keep the distinction between ontological and epistemological reductionism in mind, we can see that some of those claims refer to the former and others to the latter. For the 
sake of brevity, I will rephrase Parfitian reductionism, trying to be faithful to its original meaning, and I will present it as the conjunction of two different claims. One defines ontological reductionism as Parfit understood it. The other one defines epistemological reductionism:

Ontological reductionism: A person's existence just "consists in the holding of certain more particular facts" (Parfit, 1984, p. 210) about "a brain and a body, and the occurrence of a series of interrelated physical and mental events" (Parfit, 1984, p. 211).

Epistemological reductionism: "These [more particular] facts can be described without either presupposing the identity of this person, or explicitly claiming that the experiences in this person's life are had by this person, or even explicitly claiming that this person exists. These facts can be described in an impersonal way" (Parfit, 1984, p. 210). ${ }^{3}$

Parfit used this definition to claim that all psychological continuity theorists were reductionist. He was probably wrong in that regard (see e.g. Shoemaker, 1997, p. 139). However, most narrativists engage with psychological continuity theories through Parfit's presentation. And as a result, they tend to consider that all psychological continuity theories are reductionist in a Parfitian sense. Consequently, when narrativists criticize psychological continuity theories or their reductionism, they are referring to Parfitian reductionism (see MacIntyre, 2007, pp. 216-217; Ricoeur, 1994, pp. 130-131; Schechtman, 1996, pp. 26-50). I think that it is this fact that justifies making a distinction between reductionist psychological continuity theories and non-reductionist narrative identity theories, even if the claim is probably not one hundred percent accurate.

The Schroers seem to think that their definition of reductionism is more or less equivalent to Parfitian reductionism. For example, Robert Schroer puts Parfit's Reasons and Persons as an example of a reductionist theory that reduces persons to person stages (R. Schroer, 2013, p. 339), and the Schroers, suggest that Parfit's epistemological reductionism could be read as a statement of their epistemological reductionism (J. W. Schroer $\&$ Schroer, 2014, p. 448). But we can see that the Schroers' reductionism

\footnotetext{
${ }^{3}$ It must be noted that Parfit's presentation of reductionism in Reasons and Persons is much more complex, and contains several other claims. Moreover, his views on reductionism changed over time, so that in a later article he rejected what I have labeled here as epistemological reductionism (Parfit, 1999, p. 218). However, my main focus in this article is not Parfit's views on reductionism, but the narrativist's interpretation of Parfitian reductionism as he presented it in Reasons and Persons. Therefore, I will take Parfitian reductionism to be the conjunction of these two claims, because even if it is inaccurate, I think that it reflects the way narrativists interpreted Parfit's work. I would like to thank another anonymous referee for making this clear to me.
} 
and Parfitian reductionism are not equivalent. Parfit does not try to reduce persons to person stages, as the Schroers want. He reduces persons to facts about brains and bodies. In this regard, if we were to use the type of reductionism defined by the Schroers to establish a divisive line in the debate on personal identity, they would be surprised by the results. On the one hand, as we have already seen, neither Parfit, nor Lewis (and probably, none of the main supporters of psychological continuity theories), are reductionist in the sense that the Schroers claim. On the other hand, with the exception of Rudd (2005), narrativists do not usually define themselves as non-reductionist in an absolute sense. They only reject Parfitian reductionism. Thus, even if we could say that traditional narrative identity theories are non-reductionist in a Parfitian sense, maybe some of them could be reductionist in the way that the Schroers specify. I am not saying that traditional narrative identity theories are indeed reductionist in this sense. I am only noting that they have not said anything on the issue. Thus, it might be possible that the Schroers' proposal will not only be isolated from reductionist psychological continuity theories. It could end up in the company of some other so-called non-reductionist narrative identity theory as well! Consequently, if the Schroers want their theory to remain distinctive and to be seen as a middle position between psychological continuity theories and narrative identity theories, taking the first horn of the dilemma is not their best choice.

There is another concern related to the landscape of the debate that I have not addressed yet. I have claimed (1) that Parfitian reductionism is what establishes the divisive line between reductionist psychological continuity theories and non-reductionist narrative identity theories; (2) that the kind of reductionism that the Schroers define is not equivalent to Parfitian reductionism; (3) that Parfit, Lewis, and the main supporters of psychological continuity theories are not reductionist in the sense defined by the Schroers; and (4) that some narrativists could be reductionist in the sense that the Schroers specify. However, it is still an open question whether the Schroers are reductionists in a Parfitian sense. If they were, they could just ignore the problem of circularity: even if their four-dimensionalist reductionism were untenable, they would still be reductionist (in a Parfitian sense). But this connects directly to the second horn of the dilemma: they could solve the problem of circularity by abandoning their four-dimensionalist reductionism and trying to reduce persons to something else besides person stages. Consequently, my claim is that even if the Schroers were not reductionist in a Parfitian sense before, they should accept it now, because that would be the easiest way to solve the problem of circularity. 
At first it could seem that the Schroers are not reductionist in a Parfitian sense. If they were, they would have explicitly acknowledged it. However, my intuition is that in fact they are. I think that the whole problem arises because they are following Schechtman, who considered that Lewisian four-dimensionalism entailed Parfitian reductionism and vice versa (Schechtman, 1996, p. 55). However, even if both positions entailed each other (and I suspect that they do not, but I will not discuss this here), they are still two different claims that cannot be conflated. Lewisian four-dimensionalism and Parfitian reductionism do not add up to the Schroers' reductionism. And I suspect that that belief is what is behind the Schroers' position.

Consequently, I think that if the Schroers are confronted with the fact that Lewisian four-dimensionalism and Parfitian reductionism are two different positions that must be kept separated, they will gladly abandon their definition of reductionism and endorse both, Lewisian four-dimensionalism and Parfitian reductionism. I cannot be sure if that is the case. However, there are a couple of passages that suggest that it is. For instance, in a footnote they claim that, according to Stokes, narrative accounts are committed to reductionism (J. W. Schroer \& Schroer, 2014, p. 451). However, what Stokes claims is that some narrative accounts are committed to four-dimensionalism (Stokes, 2012). As noted above, Robert Schroer says that, according to Parfit's Reasons and Persons, "persons are aggregates of person stages" (R. Schroer, 2013, p. 339). But this does not seem to be right. In Reasons and Persons Parfit does not speak about person stages a single time. And finally, as mentioned above as well, the Schroers suggest that Parfit's claims about his epistemological reductionism could be read as statements of their epistemological reductionism (J. W. Schroer \& Schroer, 2014, p. 448). These passages suggest that the Schroers are not appropriately distinguishing between four-dimensionalism and Parfitian reductionism and that they think that they are more or less the same thing. If this is true, then we could expect the Schroers to accept Parfitian reductionism as a way to solve the problem of circularity.

If the Schroers decide to endorse Parfitian reductionism, thus taking the second horn of the dilemma, the perspectives for their theory are much more promising. At least, in principle: they would not need to make any further changes in their theory. They could still endorse four-dimensionalism, maintain the same criterion of personal identity and define narrativity in the same way they do. However, they may be tempted to take the second horn of the dilemma without endorsing Parfitian reductionism. They could decide to accept a different type of reductionism instead. It is a possibility. 
And in the light of what I will say in the rest of this article, a tempting one. However, they must consider two things: (1) That newly proposed reductionism should be able to establish a distinction between reductionist psychological continuity theories and non-reductionist narrative identity theories. Because it is unlikely that they will find statements by the philosophers involved, at least they will need to prove that psychological continuity theories are compatible with that type of reductionism, while narrative identity theories are not. (2) That newly proposed reductionism should be able to avoid at least some of the problems that affect Parfitian reductionism, as I will present them in the last section. If not, there would be no reasons to prefer that other reductionist account over Parfit's one.

The Schroers might argue that they do not need to endorse a reductionist stance that is compatible with all psychological continuity theories. They could say that all they need to prove is that all psychological continuity theories accept one or another type of reductionism, and thus that they all are reductionist (although in different senses). However, if they take this path, they will need to prove that all narrative identity theories are non-reductionist in an absolute sense. And I think that this is just not true. Moreover, I even think that the vast majority of narrativists would accept some kind of ontological reductionism, as long as it is understood as a rejection of Cartesian dualism. However, considering that only Rudd has claimed to be a non-reductionist in an absolute sense, I think that the burden of proof is on the side of the Schroers.

I consider that accepting Parfitian reductionism is the most obvious move for the Schroers. Thus, in what follows, I will analyze the problems that the Schroers would face if they decided to accept Parfitian reductionism. In this sense, hereafter when I talk about reductionism it should be understood that I am referring to Parfitian reductionism as I defined it above.

\section{Reductionist narrativism Vs. Non-reductionist narrativism}

The Schroers compare their theory to non-reductionist narrative identity theories with regard to two problems: the problem of error and the problem of fission. Their claim is that their reductionist account has an advantage over non-reductionist narrative accounts because their theory can deal with these problems more satisfactorily than non-reductionist narrative identity theories. However, it seems to me that the Schroers underestimate the resources that are available to non-reductionists narrative theories. At the 
same time, they ignore the problems that affect their account for accepting reductionism. Problems that traditional narrative identity theories do not have to face.

In the rest of this paper I intend to prove that non-reductionist narrative theories are preferable to the Schroers' reductionist account. To do so, first I will need to present what I mean by non-reductionist narrative accounts. Then, I will show how these non-reductionist accounts can deal with the problem of error and the problem of fission. To end with, I will highlight some of the problems that the Schroers' theory has in virtue of accepting reductionism.

\subsection{Non-reductionist narrativism}

Narrative theories of personal identity were born in the 1980's and they remained mostly unchallenged until the 2000's. As Olson and Witt correctly point out, most narrativists are more concerned about the characterization question of personal identity (what sort of person I am) than the persistence question (Olson \& Witt, 2019, pp. 419-420). However, some of them -I would dare to say that the most important of them- believe that their accounts of the characterization question have implications for the persistence question as well (see e.g. Dennett, 1991; MacIntyre, 2007; Ricoeur, 1994; Schechtman, 2014). They rarely have said very clearly what their response to the persistence question would be, and therefore it can be difficult to know. Olson and Witt have made a praiseworthy attempt to formulate what this response could be. However, I think that their characterization misinterprets some important aspects of narrative theories. I will try to present a better case for persistence narrativism, gathering aspects of some of their better known supporters.

A rough version of the narrativist account of the persistence question could be as follows:

Person $\mathrm{X}$ at time $\mathrm{t}_{2}$ is numerically identical to something $\mathrm{Y}$ at time $\mathrm{t}_{1}$ if:

(1) There is a narrative negotiation between X's self-narrative and X's acquaintances' narratives of X's life.

(2) That narrative negotiation establishes that $\mathrm{X}$ is $\mathrm{Y}$.

This criterion is akin to what Olson and Witt call "social narrativism" (Olson \& Witt, 2019, pp. 428-429). However, contrary to them, I do not believe that this is some new attempt to save narrative theories from recent criticisms. What they call social narrativism has been at the core of the narrative project since its very beginnings, and has figured in one way or another in the specific theories of some of the main philosophers behind 
narrativism (see e.g. Dennett, 1991, p. 429; MacIntyre, 2007, p. 213; Ricoeur, 1994, p. 160; Schechtman, 2014, p. 103).

Having clarified that, in order to fully understand the narrativist account of the persistence question, the first thing that is necessary to explain is what narrativists mean with the concept of "narrative". And contrary to what it may seem, it has nothing to do with texts. Narrativity, in the context of narrative theories of personal identity, is understood as a way of understanding the mind. It is intended to highlight the fact that our mental states do not usually present themselves to us as just one thing after another. They present themselves as being intelligible. And this intelligibility comes from the fact that we have a general knowledge of what happened in the past and what we can expect in the future. That general knowledge is what allows us to make sense of what is going on in the present. In this regard, when narrativists claim that we understand ourselves in narrative form, or that we have a self-narrative, they do not mean that we talk about our lives in narrative form, or that we have a disposition to give a narrative account of our lives (Olson \& Witt, 2019, p. 422). It means that we experience our life as an ongoing narrative, making sense of ourselves as we see that our present fits into the general narrative of our existence. In this regard, the narrative we experience our lives through is the "organizing principle of our lives. It is the lens through which we filter our experience and plan for actions" (Schechtman, 1996, p. 113). Our narrative self-understanding may be expressed later with words and told as a narrative. But that is a second step. Coherently, the same applies to our narrative understanding of other persons besides ourselves. It is not a narrative that we tell, but a certain way of understanding others.

A second aspect that is important to clarify is that our narrative self-understanding is always embodied in a double sense (see e.g. Menary, 2008; Ricoeur, 1994). First, we have the kind of self-understanding that we have because we have the kind of body that we have, i.e. a human body. If we had a very different kind of body — for example, if we were immortal, or if we could be at two different places at the same time- we would have a very different understanding of ourselves. Secondly, each of us grasps their life in the way we do because we have our specific body. For example, if we had been way more attractive than we are - or way less- we would see ourselves in a different way. This is why Ricoeur rejected the kind of thought experiments that populated the works of psychological continuity theorists: by focusing on the brain they were ignoring the sense of mineness that we have over our own bodies, and that greatly affects our self-narratives (Ricoeur, 1994, p. 132). 
A third feature of narratives that is important to understand is that our self-narratives are always embedded in a certain social context. We do not exist in a vacuum, and thus we cannot just invent our self-narratives in the way we want. Since the moment we are born our parents begin to understand and interpret our behavior, setting certain parameters and expectations of what our life should be (MacIntyre, 2007, p. 213). That is, they have a narrative understanding of ourselves. And that narrative understanding influences our development not only in the first years of our existence. It continues to operate in both explicit and implicit ways through our whole life. Obviously we are not the passive result of whatever social environment we happen to live in. But we are not hermits either. We cannot understand ourselves in a such a way that is immune to what other persons say and expect about us. We are social beings, who engage in meaningful interactions with their peers. And those interactions affect our self-narratives, just as much as our self-narratives influences our acquaintances' narrative understanding of ourselves.

We can see now that the concept of "narrative" tries to knit together our mental capacities with some biological and social aspects of our existence. In this regard, we can say that "person" is a cluster concept that involves a number of mental, biological and social properties (the properties that are needed to have an embodied and embedded self-narrative), none of which is in itself necessary or sufficient for our persistence, but all of which contribute to it in prototypical cases (cf. Schechtman, 2014, pp. 147-151). As an analogy, we can think about the contribution of individual atoms to the persistence of a certain object - a rock, for example. Certainly, none of the atoms in a rock is in itself necessary or sufficient for the persistence of the rock. But if all the atoms are still in their place, the rock persists. The rock could persist even if it lost some of its atoms, although its persistence would be compromised at a certain point. The same is true of persons. None of the characteristics that make us persons is necessary or sufficient for our persistence. In prototypical cases, we posses all those characteristics. We can still persist if we lose some of them. However, at some point, our persistence would be compromised.

\subsection{Non-reductionist narrativism, the problem of error and the problem of fission \\ Now that we know what I mean with non-reductionist narrativism, we can begin with the comparison. The Schroers claim that non-reductionist narrative identity theories do not have resources to deal with two problems}


that affect neo-Lockean accounts of personal identity. The first problem is what they call the problem of error, and it consist in the fact that we can be mistaken about our identity. The second problem is the problem of fission, that has to do with what happens to personal identity in scenarios where a person splits into two. As I will show in this section, narrativists can deal with those two problems at least as good as psychological continuity theories and the Schroers' theory do.

I will address the problem of error first. All neo-Lockean theories defend that our identity depends on our psychological properties. Thus, they all have problems to explain what happens with cases in which a person is self-deceived, or mad, and claims to be someone who he clearly is not. They need a way to distinguish between true and delusional claims regarding one's own personal identity.

According to the Schroers, their theory can meet this challenge thanks to the second condition of their identity criterion. That is, the condition that states that narrative continuity must have the right kind of cause. However, the "right kind of cause" can be interpreted in different ways. The Schroers are unclear about what they mean with it, although I suspect that they are interpreting this condition according to what Parfit called "the wide version" of psychological continuity theories (Parfit, 1984, p. 207). That is, they think that the "right cause" is "any reliable cause". In this regard, they refine their point with the help of a couple of thought experiments (J. W. Schroer \& Schroer, 2014, p. 465). In the first scenario, we are asked to imagine what would happen if someone became delusional and by chance became narratively continuous with Napoleon. In the second scenario, they turn to a case in which someone's psychology (e.g. Napoleon) is reliably transplanted into a different body and brain. According to the Schroers there is an obvious difference between both cases. And their theory can account for that difference. In the first scenario, even if the delusional person is indeed narratively continuous with Napoleon, he would not be Napoleon, because this continuity would not have been caused in the right way. In the second scenario, narrative continuity would have a reliable cause, and thus the person with Napoleon's psychology would indeed be Napoleon.

As I said, according to the Schroers, there is an obvious difference between the two scenarios that they depict. And their theory can account for that difference. Therefore, the Schroers' claim, if traditional narrative theories want to be as good a solution to the persistence question as their own theory, narrativists must be able to account for that difference too. However, before even analyzing what narrative theories could say about 
those two scenarios, we can see that the criticism departs from an unsupported claim. The Schroers say that there is an obvious difference between the two cases, because nobody could accept that the delusional person is Napoleon, and "by and large" (J. W. Schroer \& Schroer, 2014, p. 465) philosophers would agree that in the second scenario the person claiming to be Napoleon would indeed be Napoleon. However, that does not seem to be true, as only those who endorse the wide version of psychological continuity theories would interpret the two cases as being different. Those who endorse a different version of psychological continuity theories (e.g. Parfit) and those who endorse animalism or some other physical continuity theory (e.g. Olson) would not see a difference between both cases. In this regard, it is hard to see why traditional narrative theories should establish such a difference. Narrativists do not need to agree with the Schroers on how to interpret these two specific cases. All they need is a well-supported criterion to distinguish between true and delusional claims regarding one's own personal identity. And they can do it if they follow what Schechtman says on the topic (see Schechtman, 1996, pp. 119-130).

Schechtman's solution to the problem of error is what she calls the "reality constraint". This constraint states that an identity-constituting narrative must cohere with some relevant objective facts regarding our human bodies. Independently of how we conceive the relationship between the concepts of "person" and "human being", it is evident that every single person that we know of has an intimate relationship with a human body. Moreover, not a single person has ever switched bodies with another person. Therefore, an identity-constituting narrative must acknowledge this special connection that every person has with their own body. This does not mean that a person cannot switch bodies. But if they do, their narrative must contain a good and accurate explanation of how that could have happened. The Schroers ask what could count as a good explanation here. The answer lies in the social aspect of personhood: if personal identity depends both on our self-narrative and in other persons' narratives about ourselves, a good explanation of how we have switched bodies will be an explanation that can convince those other persons that we are not delusional. The Schroers will probably complain, and ask about the objective facts that could be offered to convince those persons that we have switched bodies. However, it is not possible to give a complete list of such facts. Personhood has a social dimension, and what could count as a good explanation in this case depends not only on objective facts, but also on social beliefs about those facts. Consequently, what would count as a good explanation here is subject to 
the empirical analysis of social beliefs regarding personal continuity, and no arm-chair philosophical account could overcome that.

Much more could be said with regard to how non-reductionist narrative identity theories deal with the problem of error. However, I think that what has been said is enough to prove that they have resources to deal with this problem at least as good as the Schroer's account.

Let's move on to the problem of fission. This problem arises from cases "where a hypothetical surgical procedure creates two persons out of one, where each new person seemingly has equal claim, in virtue of her self-told narrative, to being the original person" (J. W. Schroer \& Schroer, 2014, p. 467). According to the Schroers, traditional narrative theories do not have a way to deal with this problem. Conversely, the Schroers have two options available to them. First, I will analyze the options that the Schroers have to face fission cases, showing that one of them is not really available to them, while the second one is highly undesirable. Then, I will explain why traditional narrative theories are immune to this problem.

The first option that they present is based on Lewis' four-dimensionalist account of personal identity. According to Lewis, two different persons can share some of their person stages, just as two roads can share some spatial parts (Lewis, 1983, pp. 62-63). Thus, in a fission case we can consider that two persons are sharing their person stages up to a certain point in time. After that, they split and continue existing by having non-shared person stages. This is an attractive response - although it is not free of complications (see Parfit, 1976) - however it is not available to the Schroers. Their criterion of personal identity says that two person stages belong to the same person if there is narrative continuity between them and "there is no branching". The case of fission is a case where there is branching. Thus, they cannot say that a pre-fission person stage and a post-fission person stage are part of the same person. The Schroers are committed to say that in a case of fission the pre-existing person ceases to exist.

This leaves the Schroers with the only alternative of accepting the Parfitian solution to the problem of fission: embracing the fact that personal identity does not matter. Parfit included a no-branching clause in his identity criterion, just as the Schroers did. And consequently he claimed that a fission case is always a case in which the original person is destroyed and two different persons, who are psychologically continuous with the original person, are created. However, if we were going to be the subjects of a fission case, our destruction should not be seen as a threat, because what really matters when it comes to survival is not identity, but psychological 
continuity. Therefore, if after the fission there will be two persons that will be psychologically continuous with us, we should not see our destruction as being the same as death, but as being a double survival (Parfit, 1984, pp. 261-262). I will say a little more about this in the final section of the paper. For now, I will just point out that endorsing the claim that personal identity does not matter is highly counterintuitive. And as such, we should be suspicious of its suitability.

Fission cases are one of the most troubling challenges in personal identity. And the solutions that the Schroers have available to them are far from being desirable. In this regard, even if non-reductionist narrativists did not have a have way to address this problem, it would not be so relevant to our comparison: not having a way to solve a problem is more or less equivalent to having a very undesirable solution to it. However, I think that non-reductionist narrative theories are immune to the problem of fission.

First, we must note that the Schroers' theory, as most psychological continuity theories, is very vulnerable to this problem because from their position it is easy to concoct situations in which two persons ( $\mathrm{X}$ and $\mathrm{Z}$ ) would have equal claim to being identical to a single past person (Y). If personal identity depends only on psychological properties, it is easy to imagine a device that is capable of duplicating Y's psychological properties in (at least) a reliable way. However, this kind of cases do not necessarily affect narrative theories. As we have already said, personal identity depends not only on one's self-narrative, but also on other's persons narratives about oneself. In this regard, it is not enough to duplicate Y's mental properties to have a fission case for non-reductionist narrative theories: it is also necessary that the rest of society sees $\mathrm{X}$ and $\mathrm{Z}$ as having equal claim to the identity of $\mathrm{Y}$. This implies that $\mathrm{X}$ and $\mathrm{Z}$ must have not only the same self-narrative, but they must also share any property that could motivate society to say that one of them has a better claim to the identity of Y. For example, if $\mathrm{X}$ has Y's original body, while Z has someone else's body, or a duplicate of Y's original body, we could expect society to believe that $X$ has a better claim to being identical to Y. If this were the case, then society would not take Z's claims seriously and we would not have a fission case.

We could still imagine a situation in which neither $\mathrm{X}$ or $\mathrm{Z}$ would have a better claim to being Y. I can think of some cases that could be discussed (a person who splits into two like an amoeba, a double brain hemisphere transplant...), but I do not think that any of them would make a difference: in spite of what the Schroers claim, Schechtman has offered a compelling explanation of why narrative theories are immune to the problem of fission (Schechtman, 2014, pp. 159-166). 
As it is well-known, one of the defining features of neo-Lockean accounts of personal identity is their endorsement of the claim that personal identity is tightly linked to moral responsibility and other ethical and practical issues. This endorsement is especially important for narrative theories, as they appear as a response to Parfit's recently mentioned claim that personal identity is not what matters (see e.g., Ricoeur, 1994, pp. 129-139; Schechtman, 1996, pp. 60-66). According to Parfit, personal identity is indeed linked to certain moral concerns, but only vicariously. Personal identity is based on psychological continuity, and it is psychological continuity that is directly connected to the moral concerns in question. Thus, according to Parfit, if we had psychological continuity but not personal identity, as it happens in fission cases, the link between psychological continuity and those moral concerns would still hold, but personal identity would no longer had any connection to those moral concerns, thus justifying his claim that personal identity is not what matters. On the opposite side, Schechtman defines the concept of "person" by establishing a direct link between personal identity and those moral concerns. In this regard, she claims that a person is a unified locus of our person-related concerns, and that thus a person persists over time as long as that unified locus persists (Schechtman, 2014, p. 159). In fission cases, there is no "unified locus" any more. What once was a unified locus, has split into two and thus has ceased to exist. As a consequence, fission cases destroy personal identity. But not because some arbitrary condition concocted to solve the problem, as it happens in Parfit's theory with the no-branching clause, but because one of the defining features of personhood is irremediably lost when someone splits into two.

The details of this solution to the problem of fission can be difficult to grasp without examples. However, for reasons of space, I refer the reader to Schechtman's book, and expect that what has been said is enough to show that narrative theories are in a better position to address the problem of fission than the Schroers' reductionist theory (see also Muñoz Corcuera, 2020).

\subsection{Some problems for reductionist narrativism}

I have shown that non-reductionist narrativism can deal with the two problems presented by the Schroers in a better way than they acknowledged. To conclude, I will highlight three problems that affect the Schroers proposal in virtue of being reductionist, and that non-reductionist narrativist do not have to face. The first two problems are important, but probably they could be easily solved. For its part, the third problem presents a more serious challenge. 
The first problem that I will present is what I call the we-might-all-bedead problem. This problem arises from the second and third conditions of their criterion of personal identity (see above). With regard to the second condition, the Schroers seem to think that the right kind of cause for mental states to be causally related does not imply the continuity of the same brain. But if this is true, then any psychological duplicate of me will have the same right to claim my identity than my original body. If a psychological duplicate of me suddenly appeared somewhere while I am still alive, that psychological duplicate would have the same right to claim my identity than my original body, and thus it would be a case of branching. ${ }^{4}$ There would be two persons who have an equal claim to being me. But because of the third condition, the Schroers think that branching destroys personal identity. Thus, if a psychological duplicate of me were to appear somewhere in the universe, that duplicate would not be identical with me. But neither would be my original body anymore! Now, let's imagine that an evil corporation has managed to create an exact psychological duplicate of everyone on Earth in their secret laboratory in Mars. Five minutes ago they switched on all those duplicates. According to the Schroers, everyone on this planet died when those psychological duplicates came online. Since we cannot know if that has actually happened and there is a psychological duplicate of everyone somewhere in Mars, the Schroers' theory implies that we might all have died without anyone noticing.

A second problem that they will have to face is what I call the zombie survivor problem. This problem is specifically related to Parfitian reductionism. As we saw, Parfit decided to refer to mental properties with the term "event". And this decision covertly implies a reduction of mental properties to physical or functional properties (Shoemaker, 1997, p. 139). The Schroers thus have to face a problem related to the hard problem of consciousness. They need either to explain how phenomenological properties can be reduced to physical or functional properties, or they will have to accept that phenomenology is not necessary for the existence of persons. It is unlikely that they will explain how phenomenological properties can be reduced to physical or functional properties. But if they accept that phenomenological properties are not necessary for the existence of persons, then they are committed to accept that we could survive without them. Even if we are not zombies now, we could be zombies in the future.

\footnotetext{
${ }^{4}$ In order to avoid this conclusion, the Schroers would need to endorse something akin to Nozick's closest continuer theory (see Nozick, 1981, pp. 29-37). Because they do not, they cannot establish a difference between the person having my original body and the duplicate.
} 
That would be the case, for example, if our mental properties were uploaded to a computer system that did not support conscious experience. Or if there were a "consciousness blocker" device that could turn anyone into a zombie. In those scenarios, those hypothetical future beings would have the kind of psychological properties that psychological continuity theories always talk about (memories, beliefs, intentions, desires...), and thus they would be psychologically continuous with ourselves. However, they would be zombies. That is, they would lack phenomenological consciousness. But conscious experience is one of the most relevant features of persons. It also seems to be in the basis of the importance that we attach to personal identity. We want to survive because we want to be there in the future to experience it. It would not count as survival, or at least, as a survival we could care about, if we were there in the future but we were barred from experiencing anything.

Finally, the Schroers will have to face a well-known problem that affects psychological continuity theories: what Parfit called the extreme claim (Parfit, 1984, p. 307). The extreme claim says that, if we accept reductionism, then we have no reasons to be concerned about our future. We only have reasons to be concerned about our future if we will exist in the future, if there will exist someone in the future that will be identical to us. Moreover, qualitative similarity cannot justify our concern for our future. It is not enough that there will be someone very similar to us: it must be us who will be there. Reductionist psychological continuity theories seem to be committed to accept the extreme claim because they collapse the distinction between numerical identity and qualitative similarity. They define personal identity in terms of psychological continuity. And psychological continuity is nothing more than a certain type of qualitative similarity with regard to mental states (Schechtman, 1996, p. 52). Being so, they cannot distinguish between someone being me and someone being like me, because for reductionist psychological continuity theories both things are the same. If someone is like me, then it is me.

At this point we can go back to the famous Parfitian claim that personal identity is not what matters. At first it can seem that this claim offers somehow a response to the extreme claim. The extreme claim presupposes that it is only rational to care about one's future if we will be there in the future. That is, it assumes that personal identity is what matters. But according to Parfit, what matters is not personal identity, but psychological continuity. Thus, it may be that psychological continuity can justify our concern for our future. It may be that if there will be someone in the future that will be 
psychologically continuous with me, then it is rational for me to care about my future (Parfit, 1984, p. 311). However, contrary to what Parfit seems to think, this does not offer any help to avoid the extreme claim. Psychological continuity, as it is defined by reductionist psychological continuity theories, may be of some importance, but is not enough to justify our concern for our future because it is nothing more than a certain type of qualitative similarity. And if I will not be there in the future, it does not matter whether there will be someone very similar to me (Schechtman, 1996, p. 63). Thus, Parfitian reductionism entails the extreme claim. And the Schroers seem to be committed to accept it too.

Parfit claimed that it was not a problem for reductionists to accept the extreme claim. In fact, accepting it would be a good thing: it would dissolve the conflict between self-interest and interest in others, as we would have the same reasons to work for the benefit of our own future than to work for the benefit of others (Parfit, 1984, pp. 307-320). However, rather than a benefit, this seems to be a highly counterintuitive consequence. And this is especially undesirable for psychological accounts of personal identity, as the main reason to endorse them is precisely their intuitive appeal. Psychological accounts of personal identity are attractive because they seem to offer the best way to capture our intuitions with regard to the connections between personal identity and some important ethical issues (Schechtman, 1996, p. 2). Endorsing the claim that personal identity is not what matters, and that our concern for our future is not justified does not seem to be the expected outcome. And before biting that bullet it would be reasonable to see if any other theory can do it better.

\section{Conclusions}

The Schroers defended two claims. (1) That it is possible to accept reductionism and narrativism at the same time. And (2) that doing so would result in an improved account of personal identity. I think that they succeeded with regard to the first claim. Narrative accounts of personal identity had been seen for a long time as being incompatible with a commitment to reductionism. And the Schroers showed that both positions can be successfully wedded. However, as I have demonstrated, the specific type of reductionism that they endorsed is subject to a problem of circularity: they wanted to reduce persons to person stages, but they conceived person stages as being short-lived persons. This puts them in front of a dilemma: either they give a 
new definition of the concept of person stage, or they try to reduce persons to something else besides person stages. It seems unlikely that that they can succeed if they take the first horn of the dilemma. And if they take the second horn instead, their best option would be to accept Parfitian reductionism. However, if they do so, their reductionist narrative account will have much more problems than non-reductionist narrative accounts. In light of my argument, the Schroers should either present a new and improved reductionist narrative account, or accept that non-reductionist narrative theories are better suited to account for the problem of personal identity.

\section{Bibliography}

Dennett, D. C. (1991). Consciousness Explained. New York, Little, Brown and Company.

Johnston, M. (2010). Surviving Death. Princeton, NJ, Princeton University Press.

Lewis, D. K. (1983). Survival and Identity. In Philosophical Papers (Vol. 1, pp. 55-77). Oxford, Oxford University Press.

Locke, J. (1975). An Essay Concerning Human Understanding. Oxford, Oxford University Press.

MacIntyre, A. (2007). After Virtue: A Study in Moral Theory (3rd ed.). Notre Dame, IN, University of Notre Dame Press.

Menary, R. (2008). Embodied Narratives. Journal of Consciousness Studies, 15(6), 63-84.

Muñoz Corcuera, A. (2020). Las teorías narrativas frente a los casos de duplicación: Una defensa de la determinación de la identidad personal. ÉNDOXA: Series Filosóficas, 45, 175-198.

Noonan, H. (2003). Personal Identity (Second Edition). London, Routledge.

Nozick, R. (1981). Philosophical Explanations. Cambridge, Mass, Harvard University Press.

Olson, E. T., \& Witt, K. (2019). Narrative and persistence. Canadian Journal of Philosophy, 49(3), 419-434.

Parfit, D. (1976). Lewis, Perry, and What Matters. In A. O. Rorty (Ed.), The Identities of Persons (pp. 91-107). Berkeley, University of California Press.

Parfit, D. (1984). Reasons and Persons. Oxford, Oxford University Press.

Parfit, D. (1999). Experiences, Subjects, and Conceptual Schemes. Philosophical Topics, 26(1-2), 217-270. 
Ricoeur, P. (1994). Oneself as Another. Chicago, University of Chicago Press.

Rudd, A. (2005). Narrative, Expression and Mental Substance. Inquiry: An Interdisciplinary Journal of Philosophy, 48(5), 413-435.

Schechtman, M. (1996). The Constitution of Selves. Ithaca, NY, Cornell University Press.

Schechtman, M. (2014). Staying Alive: Personal Identity, Practical Concerns, and the Unity of a Life. Oxford, Oxford University Press.

Schroer, J. W., \& Schroer, R. (2014). Getting the story right: A Reductionist narrative account of personal identity. Philosophical Studies, 171(3), 445-469.

Schroer, R. (2013). Reductionism in Personal Identity and the Phenomenological Sense of Being a Temporally Extended Self. American Philosophical Quarterly, 50(4), 339-356.

Shoemaker, S. (1984). Personal Identity: A Materialist's Account. In Personal Identity (pp. 67-132). Oxford, Basil Blackwell.

Shoemaker, S. (1997). Parfit on Identity. In J. Dancy (Ed.), Reading Parfit (pp. 135-148). Oxford, Blackwell.

Stokes, P. (2012). Is Narrative Identity Four-Dimensionalist? European Journal of Philosophy, 20(Supplement 1), 86-106. 